\title{
The effect of chloroquine phosphate on the pharmacodyanmic activity of ampicillin trihydrate against Staphylococcus aureus
}

\author{
Awofisayo Oladoja Abosede ${ }^{1}$ and Igbeneghu Oluwatoyin Abimbola ${ }^{2 *}$ \\ ${ }^{1}$ Department of Pharmaceutical and Medicinal Chemistry, University of Uyo, Uyo, Akwa lbom State, Nigeria. \\ ${ }^{2}$ Department of Pharmaceutics, Obafemi Awolowo University, Ile-Ife, Osun State, Nigeria.
}

Accepted 6 December, 2013

\begin{abstract}
The effect of chloroquine phosphate on the pharmacodyanmic activity of ampicillin trihydrate against Staphylococcus aureus NCTC 6571 was investigated using physicochemical and microbiological assay techniques. The physicochemical method was thin layer chromatography and ultraviolet spectrophotometry in a condition simulating normal body temperature and $\mathrm{pH}$. The microbiological assay compared the zones of inhibition of S. aureus NCTC 6571 by ampicillin trihydrate alone and in combination with chloroquine phosphate using the agar diffusion method. The kill kinetics was determined to give a dynamic assessment of the bactericidal activity of ampicilin trihydrate alone and in combination with chloroquine phosphate at various concentrations. The results showed that the zone of inhibition of $S$. aureus NCTC 6571 by ampicillin trihydrate in the presence of chloroquine was smaller than that produced by ampicillin alone. The kill kinetics revealed a significant increase in the percentage survivor of the organisms in the presence of chloroquine than with ampicillin alone. The results of the study suggest that there is no chemical interaction between the two drugs in vitro however, an antagonistic pharmacodynamic interaction exists between ampicilin trihydrate and chloroquine phosphate in vitro on S. aureus NCTC 6571.
\end{abstract}

Key words: Ampicillin trihydrate, chloroquine phosphate, drug-drug interaction, antagonism, antimalarial, antibiotic.

\section{INTRODUCTION}

Malaria amongst other protozoa infections is a major parasitic disease in the tropical and subtropical regions of the world (Breman, 2001). It constitutes a major health hazard causing a high mortality and morbidity among children and pregnant women in the region (Snow et al., 2005). Likewise, bacterial infectious disease especially diarrhoea and respiratory tract infections are major contributors to the mortality and morbidity associated with infections caused by bacteria in the region (Mathers et al., 2009; Black et al., 2010; WHO, 2010). An important symptom of these infections is fever and in some cases they are found co-occurring together (Akpede and Sykes, 1993; Berkley et al., 1999; Ayoola et al., 2005; Okunlola et al., 2012). This probable co-occurrence and presentation of fever as symptom in both cases makes physicians to treat malaria and bacterial infections in patients presenting with fever with or without diarrhoea or respiratory tract infections. A common feature therefore in the prescription from most physicians' desk is antimalarials with antimicrobials for the treatment of per- 
ceived bacterial infections in individuals with symptoms of malaria pending the results of the culture of any probable offending bacteria (Akoria and Isah, 2005).

Drug-drug interaction studies on antimicrobials and antimalarials have shown the possibility of reduced or enhanced activity of one of the drugs in the presence of the other (crowle and May, 1990; Kazzim et al., 2006). These interactions could be pharmacokinetic, physicchemical or pharmacodynamic. Pharmacokinetic interactions are caused by the effects of one drug on the absorption, distribution, metabolism, or elimination of the other drug (Rowland and Tozer, 1995; Kashuba and Bertino, 2005). Physico-chemical interactions could be due to chemical interactions between the drugs such as the physical adsorption of one drug by the other, while pharmacodynamic interactions could be due to antagonism or synergism between co-administered drugs (Kazzim et al., 2006). In vivo studies have shown a reduction in the bioavailability of ampicillin co-administered with chloroquine (Ali, 1958). This in vitro study was carried out to determine if any chemical or pharmacodynamic interaction exists between ampicillin and chloroquine when administered together.

\section{MATERIALS AND METHODS}

\section{Chemicals}

Chloroquine phosphate powder, a white, odourless, hygroscopic crystalline powder was obtained from Bond Chemical Industry, Aawe, Oyo State, Nigeria while Ampicillin trihydrate powder, a white, odourless, crystalline powder was purchased from Sigma Aldrich. Reagents used included hydrochloric acid, Silica gel $\mathrm{GF}_{254}$ Acetic acid, acetone, lodine vapour, ammonium chloride, ethyl acetate, Phosphate Buffered Saline all of which were of analytical grade.

\section{Qualitative assay of the pure powders}

The content of drug sample in each of the powders was determined according to official methods (BP 2013, U.S.P 2003).

\section{Drug-drug interaction studies}

\section{Physicochemical method}

Ultraviolet spectrophotometry: A solution containing $0.05 \% \mathrm{w} / \mathrm{v}$ ampicillin trihydrate powder in $0.1 \mathrm{M}$ hydrochloric acid (solution I) and another containing $0.00625 \% \mathrm{w} / \mathrm{v}$ chloroquine phosphate powder in $0.1 \mathrm{M}$ hydrochloric acid (solution II) were prepared. A third solution containing equimolar mixture of solutions I and II was prepared and the ultraviolet spectrum each at 200-400 nrn was determined using an ultraviolet spectrophotometer.

Thin layer chromatography: A chromatographic system consisting of Silica gel $\mathrm{GF}_{254}$ (pre coated plates, $0.25 \mathrm{~mm}$ ) as stationary phase and acetic acid: acetone $(95: 5 \mathrm{v} / \mathrm{v})$ as mobile phase employing ultraviolet lamp (254 nm) and iodine vapour for detection was used.

A solution containing $0.0323 \mathrm{~g}$ chloroquine phosphate powder dissolved in $5 \mathrm{ml}$ of acetone : $0.1 \mathrm{M}$ ammonium chloride : ethyl acetate, 3:1:1 was prepared (solution $A$ ). The ampicillin sample was a solution of $0.0229 \mathrm{~g}$ ampicillin trihydrate powder in $5 \mathrm{ml}$ of acetone : $0.1 \mathrm{M}$ ammonium chloride : ethyl acetate, 3:1:1 (solution B). A third sample was a mixture of chloroquine phosphate and ampicillin trihydrate in $5 \mathrm{ml}$ of acetone: $0.1 \mathrm{M}$ ammonium chloride : ethyl acetate, 3:1:1 (solution C). Each solution was filtered and labelled appropriately.

Each of the samples were incorporated into tubes containing $5 \mathrm{ml}$ of freshly prepared phosphate buffered saline $(\mathrm{pH} \mathrm{7.4)}$ and other tubes containing $5 \mathrm{ml}$ of $0.1 \mathrm{M}$ hydrochloric acid placed in a thermostated water bath at $37^{\circ} \mathrm{C} .1 \mathrm{ml}$ samples were then withdrawn from each of the reaction mixtures at $0,15,30,45$ and 60 min and analysed using the TLC system.

\section{Agar diffusion assay}

The test plates were prepared by inoculating $0.2 \mathrm{ml}$ of an overnight culture of $S$. aureus NCTC 6571 into $20 \mathrm{ml}$ of cooled molten Mueller Hinton Agar (Oxoid), the plates were allowed to set and harden. Holes $7 \mathrm{~mm}$ in diameter equidistant to one another were then bored into the agar using sterilized cork borer. Samples of ampicillin at concentrations of $1-6 \mathrm{ug} / \mathrm{ml}$ were introduced into the wells of the agar plates. Similarly, the organism was tested against mixtures of ampicillin and chloroquine containing $1-6 \mathrm{ug} / \mathrm{ml}$ of ampicillin and $0.08 \mu \mathrm{g} / \mathrm{rnl}$ of chloroquine. The drugs were allowed to diffuse for $1 \mathrm{~h}$ before incubation right side up at $37^{\circ} \mathrm{C}$ for $24 \mathrm{~h}$. The zones of inhibition produced after incubation was measured in $\mathrm{mm}$. The inhibition produced by the pure ampicillin alone was compared with that of the mixture of ampicillin and chloroquine. The minimum inhibitory concentration (MIC) of the pure ampicillin was graphically determined and compared with that of the mixture of ampicillin and chloroquine.

\section{Kill kinetics}

The reaction medium was prepared by transfering $1 \mathrm{ml}$ of an innoculum of $10^{8}$ organisms $/ \mathrm{ml}$ of $S$. aureus NCTC 6571 into flasks containing different concentrations of ampicillin and chloroquine to obtain a final concentration of $10^{7}$ cells per $\mathrm{ml}$ in the reaction media. The drugs were tested at concentrations of $5 \mathrm{ug} / \mathrm{ml}$ for ampicillin and $0.01-0.3 \mathrm{ug} / \mathrm{ml}$ for chloroquine. A reaction medium containing each of the two drugs alone and another containing none of the drugs were included in the experiments as controls.

The reaction flasks were incubated at $37^{\circ} \mathrm{C}$. At 0 and $6 \mathrm{~h}, 1 \mathrm{ml}$ samples were withdrawn from the reaction media, introduced into a neutralising mixture containing Penase (Difco) and viable counts were determined using the pour plate technique. The plates were incubated at $37^{\circ} \mathrm{C}$ for $24-48 \mathrm{~h}$ and number of colony forming units was counted.

\section{Statistical analysis}

Data obtained from the study was analysed statistically using paired t-test at $95 \%$ confidence interval. A $p$ value $\leq 0.05$ was considered significant.

\section{RESULTS}

The result of the thin layer chromatography of each of the drug samples is presented in Table 1 while the ultraviolet spectra are presented in Figures 1 and 2, respectively. 
Table 1. Thin layer chromatography of the pure ampicillin trihydrate and chloroquine phosphate samples.

\begin{tabular}{lccc}
\hline Drug sample & Solvent front $(\mathbf{c m})$ & Distance moved $(\mathbf{c m})$ & $\mathbf{R}_{\mathbf{f}}$ \\
\hline Ampicillin & 9.60 & 1.44 & 0.15 \\
Chloroquine phosphate & 9.60 & 4.32 & 0.45 \\
\hline
\end{tabular}

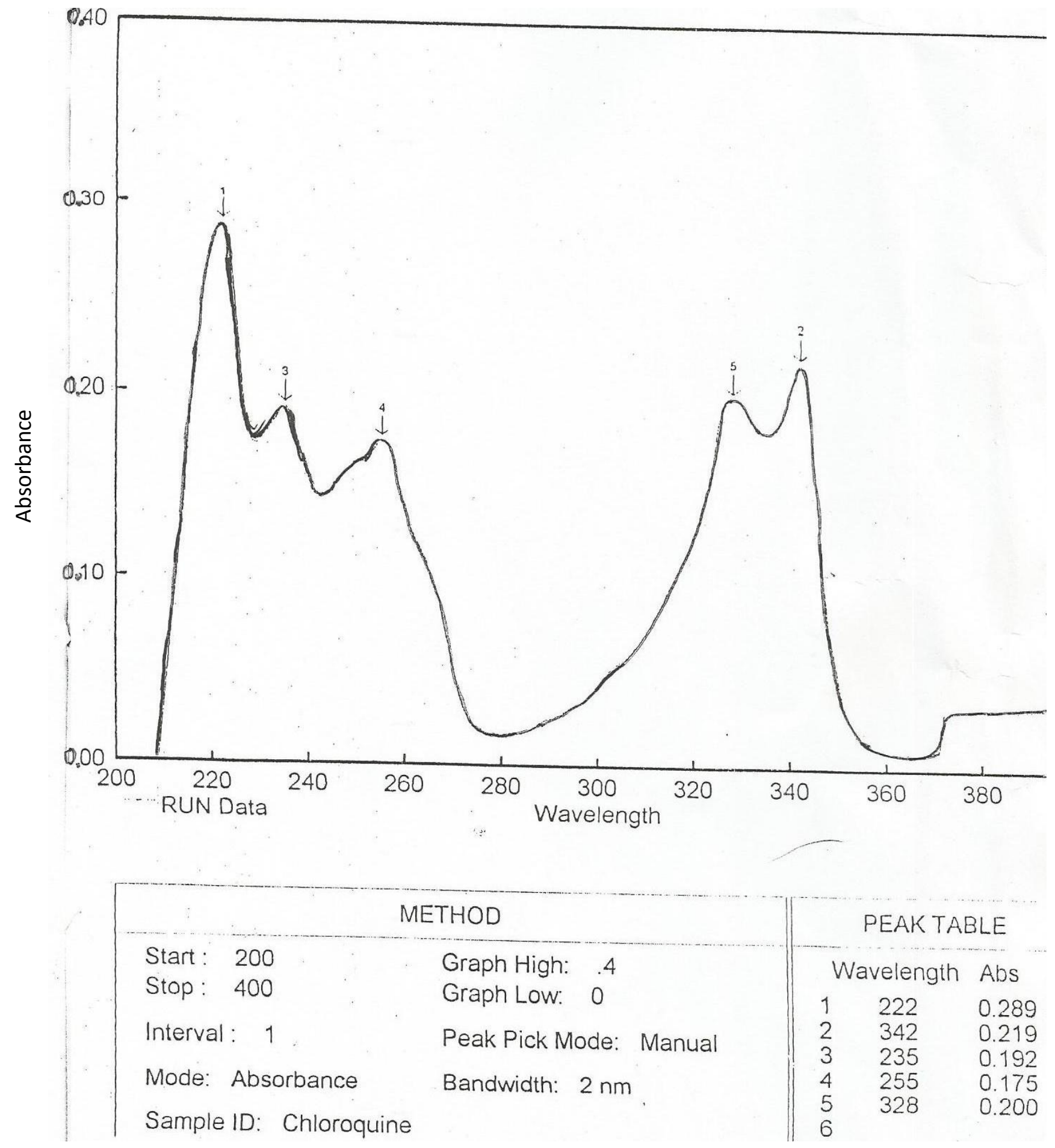

Figure 1. The ultraviolet spectrum of pure chloroquine phosphate in $0.1 \mathrm{M}$ hydrochloric acid. 


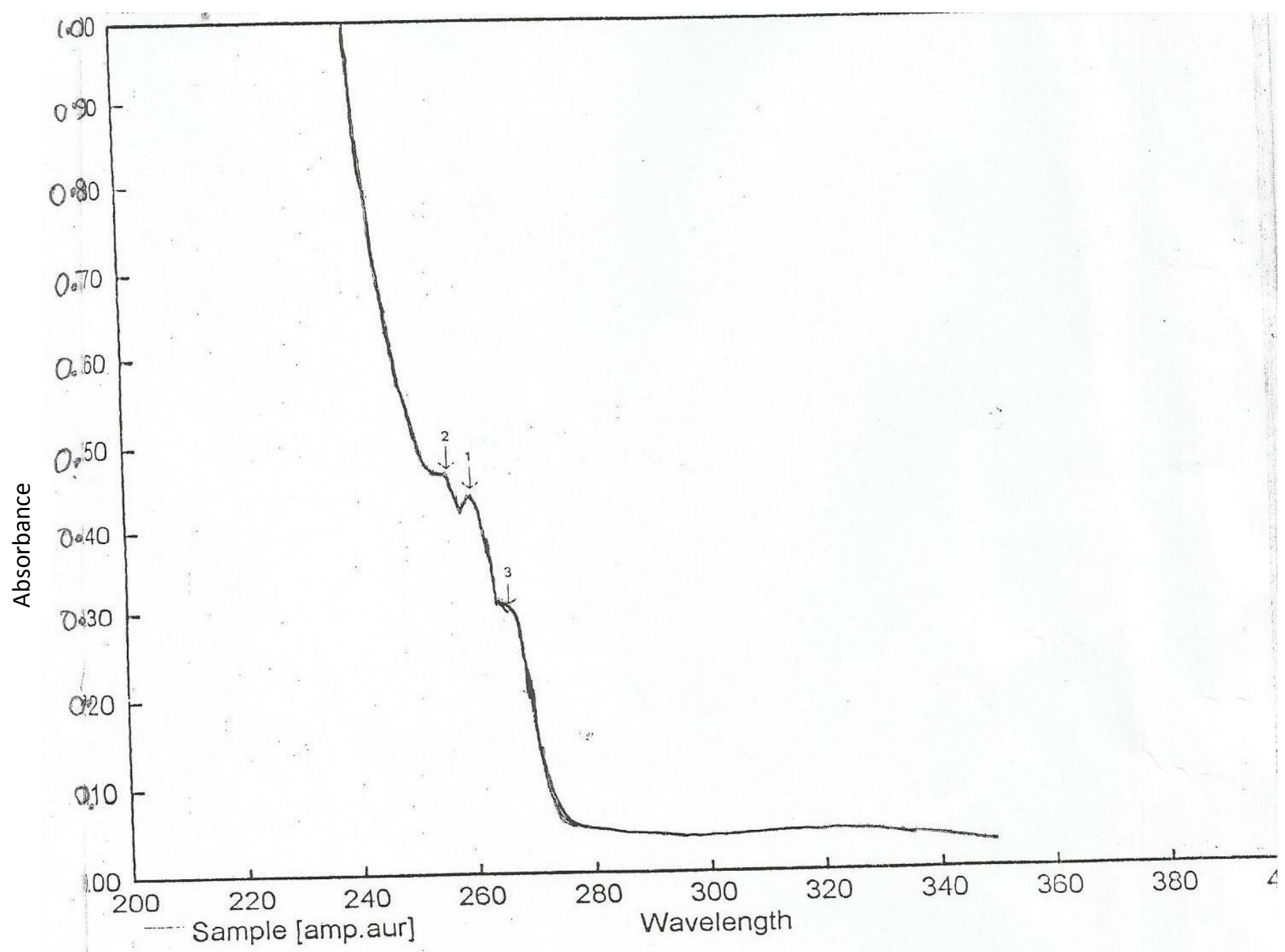

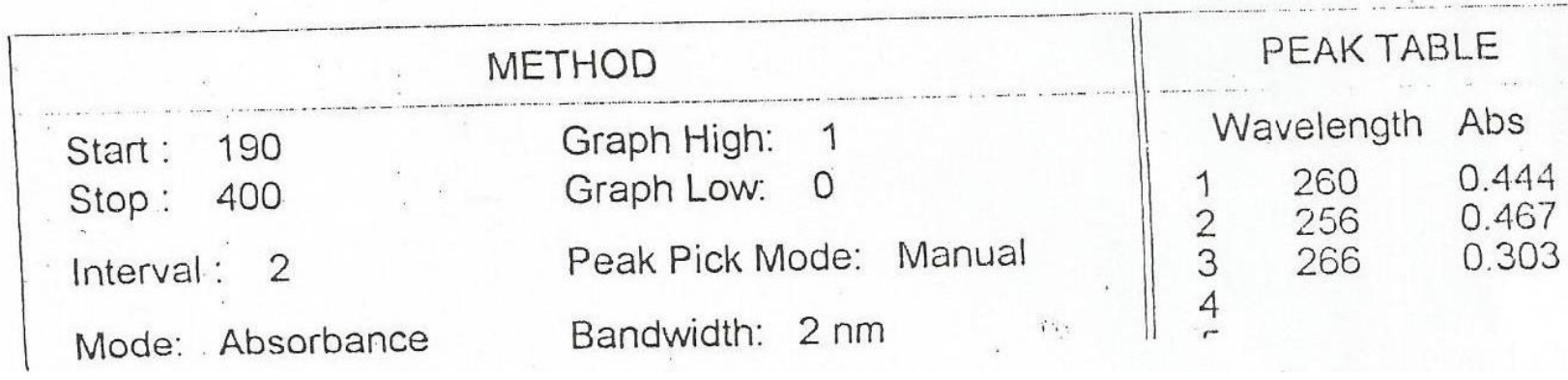

Figure 2. The ultraviolet spectrum of pure ampicillin trihydrate in $0.1 \mathrm{M}$ hydrochloric acid.

The content of chloroquine phosphate in the powder, obtained from the assay procedure was $101.52 \% \mathrm{w} / \mathrm{w}$ while the content of ampicillin trihydrate in the powder, obtained from the assay procedure was $99.70 \% \mathrm{w} / \mathrm{w}$.

The ultraviolet spectrum obtained for the solution mixture of chloroquine phosphate and ampicillin trihydrate (solution III) is presented in Figure 3 which was comparable with those of the individual drugs (Figures 1 and 2), for chloroquine phosphate and ampicillin trihydrate, respectively. The TLC result of the drugs in phosphate buffered saline and in $0.1 \mathrm{M}$ hydrochloric acid is presented in Table 2.

The result of the zones of inhibition $(\mathrm{mm})$ produced by the drugs against $S$. aureus NCTC 6571 is presented in 


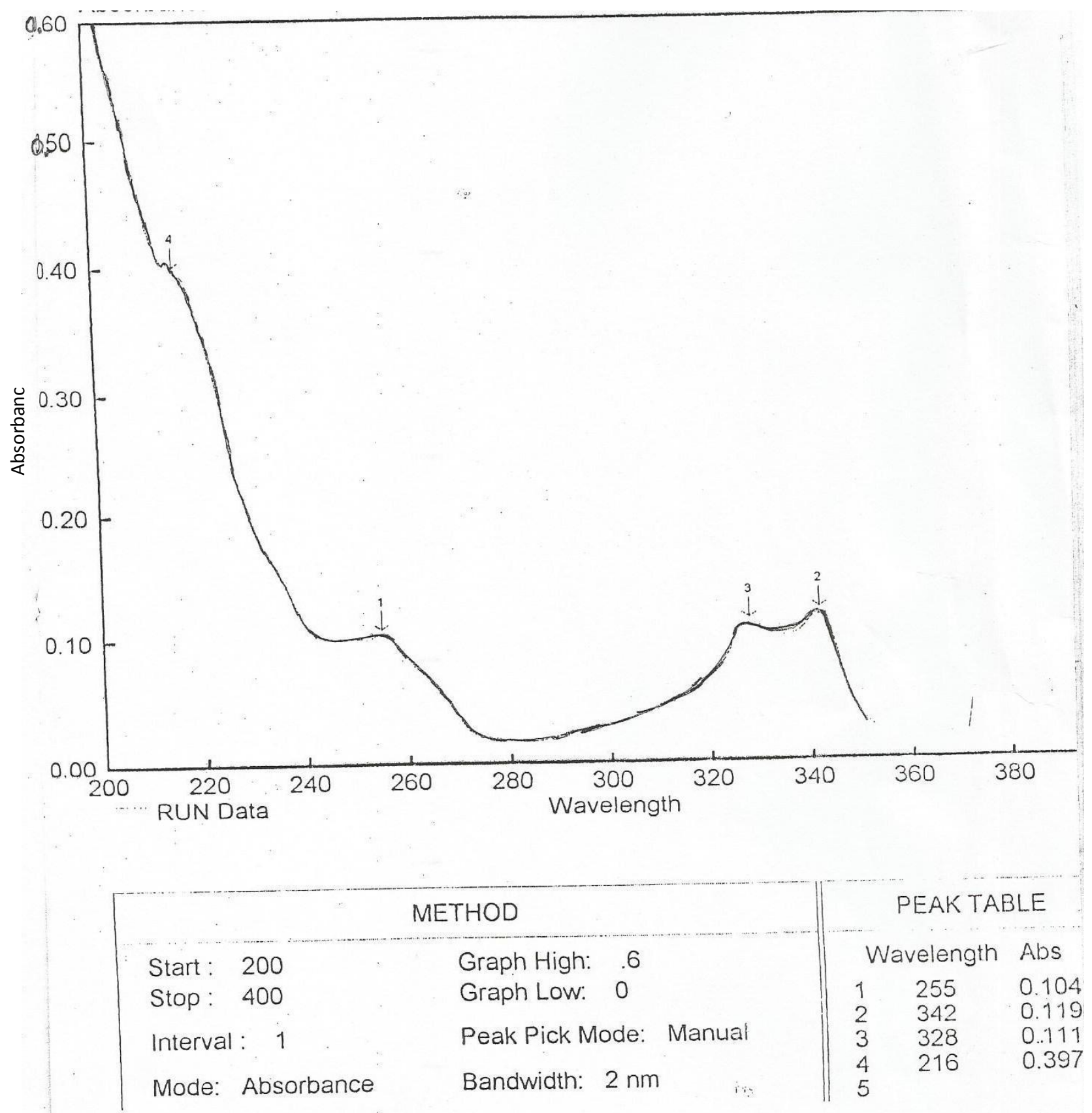

Figure 3. The ultraviolet spectrum of equimolar mixture of chloroquine phosphate and ampicillin trihydrate solution in $0.1 \mathrm{M}$ hydrochloric acid.

Table 3. Table 4 shows the result of viable bacterial count after a contact time of $6 \mathrm{~h}$ in ampicillin alone and in a mixture of ampicillin and chloroquine.

\section{DISCUSSION}

The results of the thin - layer chromatography of the two drug samples, ampicillin trihydrate and chloroquine phosphate as well as the UV spectra were similar to that of the official specifications showing that the tested drug samples were in a high state of purity. It also verified the absence of degradation products in the powder samples (BP 2013). The use of thin - layer chromatography (TLC) was to detect and monitor possible in vitro chemical interaction between chloroquine phosphate and ampicillin trihydrate, which may ultimately affect the activity of ampicillin trihydrate in vitro. This is based on possible structural interaction between chloroquine phosphate and ampicillin trihydrate. The two drugs were however 
Table 2. Thin layer chromatographic determination of ampicillin/ampicillin-chloroquine mixture in phosphate buffered saline (PBS) ( $\mathrm{pH} 7.4)$ and $0.1 \mathrm{M}$ hydrochloric acids $(\mathrm{pH} 2.0)$.

\begin{tabular}{|c|c|c|c|c|c|c|c|c|c|c|}
\hline \multirow{3}{*}{ Drug } & \multicolumn{10}{|c|}{ Time (min)/ distance moved $(\mathrm{cm})$} \\
\hline & \multicolumn{5}{|c|}{ PBS (pH 7.4) } & \multicolumn{5}{|c|}{$0.1 \mathrm{M}$ hydrochloric acids (pH 2.0) } \\
\hline & 0 & 15 & 30 & 45 & 60 & 0 & 15 & 30 & 45 & 60 \\
\hline Amp trihydrate & 0.67 & 0.67 & 0.67 & 0.58 & - & 0.62 & 0.62 & 0.62 & 0.62 & 0.62 \\
\hline Chloroquine phosphate & 0.07 & 0.07 & 0.07 & 0.07 & 0.07 & 0.07 & 0.07 & 0.07 & 0.07 & 0.07 \\
\hline Amp trihydrate + & 0.67 & 0.67 & 0.67 & 0.58 & - & 0.62 & 0.62 & 0.62 & 0.62 & 0.62 \\
\hline Chloroquine phosphate & 0.07 & 0.07 & 0.07 & 0.07 & 0.07 & 0.07 & 0.07 & 0.07 & 0.07 & 0.07 \\
\hline
\end{tabular}

Table 3. Zones of inhibition produced by test drugs against S. aureus NCTC 6571.

\begin{tabular}{lcccccc}
\hline \multirow{2}{*}{$\begin{array}{l}\text { Concentration } \\
\text { (ug/ml) }\end{array}$} & \multicolumn{6}{c}{ Diameter of zone of inhibition $(\mathbf{m m})$} \\
\cline { 2 - 7 } & \multicolumn{1}{c}{ Ampicillin alone } & Ampicillin with $\mathbf{0 . 0 8} \mathbf{~ u g} / \mathbf{m l}$ chloroquine \\
\cline { 2 - 7 } & $\mathbf{1}$ & $\mathbf{2}$ & Mean & $\mathbf{1}$ & $\mathbf{2}$ & Mean \\
\hline 6.0 & 35 & 35 & 35 & 31 & 30 & 30.5 \\
5.0 & 34 & 33 & 33.5 & 27 & 28 & 27.5 \\
4.0 & 34 & 32 & 33.0 & 26 & 26 & 26.0 \\
3.0 & 30 & 31 & 30.5 & 24 & 23 & 23.5 \\
2.0 & 28 & 28 & 28.0 & 21 & 22 & 21.5 \\
1.0 & 20 & 19 & 19.5 & 14 & 14 & 14.0 \\
PBS (pH 7.4) & 0 & 0 & 0 & 0 & 0 & 0 \\
Chloroquine 0.08 & 0 & 0 & 0 & 0 & 0 & 0 \\
\hline \multicolumn{2}{l}{}
\end{tabular}

Table 4. Viable count and percentage survivor of $S$. aureus NCTC 6571 in the presence of ampicillin and chloroquine phosphate after a contact time of $6 \mathrm{~h}$.

\begin{tabular}{llccc}
\hline \multicolumn{2}{l}{ Concentration $\boldsymbol{\mu g} / \mathbf{m l}$} & \multicolumn{2}{c}{ Viable count } & Survival (\%) \\
\hline Ampicillin & Chloroquine phosphate & $\mathbf{T}=\mathbf{0} \mathbf{~ m i n}$ & $\mathbf{T}=\mathbf{6} \mathbf{h}$ & $\mathbf{T}=\mathbf{6} \mathbf{h}$ \\
\hline 0 & 0 & $3.3 \times 10^{7}$ & $3.8 \times 10^{7}$ & 115.2 \\
0 & 0.3 & $3.3 \times 10^{7}$ & $3.0 \times 10^{7}$ & 93.8 \\
5 & 0 & $3.3 \times 10^{7}$ & $9.0 \times 10^{6}$ & 27.3 \\
5 & 0.02 & $3.3 \times 10^{7}$ & $1.9 \times 10^{7}$ & 57.6 \\
5 & 0.1 & $3.3 \times 10^{7}$ & $1.8 \times 10^{7}$ & 54.5 \\
5 & 0.2 & $3.3 \times 10^{7}$ & $1.7 \times 10^{7}$ & 51.5 \\
5 & 0.3 & $3.3 \times 10^{7}$ & $1.9 \times 10^{7}$ & 57.6 \\
\hline
\end{tabular}

separately resolved throughout the sampling period of 0 30 min implying that the two drugs did not interact chemically in phosphate buffer saline at $\mathrm{pH} 7.4$ and $37^{\circ} \mathrm{C}$. Furthermore, the gradual decrease in the $R_{f}$ value of ampicillin trihydrate by the $45^{\text {th }}$ min of sampling could possibly be due to the degradation of the drug. This is confirmed by the $60^{\text {th }}$ min of sampling in which there was a final disappearance of the spot suggesting the degradation of the ampicillin trihydrate at $37^{\circ} \mathrm{C}$ in phosphate buffer saline at $\mathrm{pH} \mathrm{7.4.} \mathrm{Chloroquine} \mathrm{phos-}$ phate was however stable throughout the sampling period of $60 \mathrm{~min}$ and is likely stabilized by the presence of buffer at $37^{\circ} \mathrm{C}$ being a phosphate salt itself. On the other hand, in $0.1 \mathrm{M} \mathrm{HCl}(\mathrm{pH} 2.0)$ at $37^{\circ} \mathrm{C}$, the $R_{f}$ of ampicillin decreased which could be attributed to the protonation of the amine side chain conferring greater stability on the drug molecule in the acidic environment. The fact that both were again resolved separately on the TLC plate suggests the absence of chemical interaction between ampicillin trihydrate and chloroquine phosphate in acidic media. This is within the detectable limit of the thin layer chromatographic technique.

The agar diffusion method revealed that the chloroquine phosphate affected the antibacterial activity of ampicillin trihydrate by a reduction in the zone of inhibition obtained, when compared with pure amipcillin alone. The observations made with the phosphate buffered saline solution of the drugs at $37^{\circ} \mathrm{C}$, which simu- 
lates in vivo body temperature and plasma $\mathrm{pH}$ of 7.4 showed that chloroquine is likely to cause a reduction in the antibacterial activity of ampicillin in vivo. Moreover, the analysis of the kill kinetics results showed that ampicillin produced a significant reduction in the percentage survivor of the test organism. The presence of chloroquine however significantly reduced the bactericidal effect of ampicillin though increase in the concentration of chloroquine phosphate in the presence of ampicillin trihydrate did not significantly increase the degree of antagonism of ampicillin trihydrate activity against $S$. aureus NCTC 6571 . Chloroquine has similarly been reported to antagonise the activity of ciprofloxacin against a strain of Pseudomonas aeruginosa in a study by Adegbolagun et al. (2008).

The modification in the in vitro antimicrobial activity of ampicillin trihydrate caused by the presence of chloroquine phosphate is an indication of a pharmacodynamic interaction between the two drugs. This pharmacodynamic interaction is between unrelated classes of compounds since ampicillin trihydrate is an antimicrobial agent and chloroquine phosphate is an antimalarial agent. Since chloroquine phosphate inhibited the activity of ampicillin trihydrate, it can be said to have an antagonistic pharmacodynamic interaction with ampicillin trihydrate.

The reduction of ampicillin bioavailablity on coadministration with chloroquine in vivo was attributed to slower gastric emptying and inhibition of gut motility produced by chloroquine (Ali, 1985). However, in vitro pharmacodynamic reduction in the activity of ampicillin trihydrate against $S$. aureus NCTC 6571 cannot be attributed to these factors. A different mechanism entirely is therefore responsible for this in vitro antagonistic action of chloroquine phosphate against ampicillin trihydrate. A possibility is a competitive inhibition of the transport mechanism responsible for the uptake of ampicillin into the bacterial cell wall where it elicits its action. There is however the need for further work to investigate the mechanism of pharmacodynamic interaction between the two drugs.

The result of this study therefore suggests that there is no form of physicochemical interaction between ampicillin trihydrate and chloroquine phosphate in vitro in acidic medium of $0.1 \mathrm{M} \mathrm{HCL}(\mathrm{pH} 2.0)$ or in phosphate buffer saline $\mathrm{pH} 7.4$ both at $37^{\circ} \mathrm{C}$ but chloroquine phosphate antagonizes the pharmacodynamic activity of ampicillin trihydrate against $S$. aureus NCTC 6571 in vitro.

\section{ACKNOWLEDGEMENT}

The authors wish to acknowledge Bond Chemical Industry, Aawe, Oyo State, Nigeria for the gift of chloroquine phosphate.

\section{REFERENCES}

Adegbolagun OM, Olajuyigbe OO, Kazzim OJ, Osho O (2008). In Vitro activity of chloroquine phosphate on the antibacterial potency of ciprofloxacin hydrochloride on the clinical isolates of some gramnegative microorganisms J. Biol. Environ. Sci. 2(5):29-34.

Akoria OA, Isah AO (2005). Treatment of malaria in health care facilities in Benin City, Nigeria. West Afr. J. Pharmacol. Drug Res. 20(1\&2):2630.

Akpede GO, Sykes RM (1993).Malaria with bacteraemia in acutely febrile preschool children without localizing signs: coincidence or association/complication? J. Trop. Med. Hyg. 96(3):146-150.

Ali HM (1985). Reduced ampicillin bioavailability following oral coadministration with chloroquine. J. Antimicrob. Chemother. 15:781784.

Ayoola OO, Adeyemo AA, Osinusi K (2005). Concurrent bacteraemia and malaria in febrile Nigerian infants. Trop. Doc. 35:34-36.

Black RE, Cousens S, Johnson HL, Lawn JE, Rudan I, Bassani DG, Jha P, Campbell H, Walker CF, Cibulskis R, Eisele T, Liu L, Mathers C (2010). Global, regional and national causes of child mortality in 2008: a systematic analysis. Lancet 375(9730):1969-1987.

Breman JG (2001). The ears of the hippopotamus: manifestations, determinants, and estimates of the malaria burden. Am. J. Trop. Med. Hyg. 64(1-2 Suppl):1-11.

British Pharmacopoeia (BP 2013). London: Cambridge University Press.

Crowle AJ, May MH (1990). Inhibition of Tubercle Bacilli in Cultured Human Macrophages by Chloroquine used alone and in Combination with Streptomycin, Isoniazid, Pyrazinamide and two metabolites of Vitamin D. Antimicrob. Agents Chemother. 34:2217-2222.

Kashuba AD, Bertino Jr JS (2005). Mechanisms of drug interactions I absorption, metabolism, and excretion in infectious disease: Drug Interactions in Infectious Diseases, Second Edition Edited by: S. C. Piscitelli and K. A. Rodvold. Humana Press Inc., Totowa, NJ. pp.1339.

Kazzim OJ, Adegbolagun OM, Osho O, Anumudu Cl (2006). Additive effects of ciprofloxacin on the in vitro activity of chloroquine against a clinical isolate of Plasmodium falciparum. Ann. Trop. Med. Para. 100(7):579-584.

Mathers CD, Boerma T, Fat DM (2009). Global and regional causes of death. British Med. Bull. 92:7-32.

Okunlola PO, Ibadin MO, Ofovwe GE, Ukoh G (2012). Co-existence of urinary tract infection and malaria among children under five years old: A report from Benin City, Nigeria. Saudi J. Kidney Dis.Transplant. 23(3):629-634.

Rowland M, Tozer T (1995). Clinical Pharmacokinetics: Concepts and Applications. 3rd ed. Baltimore, Md., Williams \& Wilkins.

Snow RW, Guerra CA, Noor AM, Myint HY, Hay SI (2005). The global distribution of clinical episodes of Plasmodium falciparum malaria. Nat. 434:214-217.

United States Pharmacopeia and National Formulary (2003). United States Pharmacopeial Convention Inc., Rockville, MD, USA, $26^{\text {th }}$ Edition.

WHO (2010). Diarrhoeal disease. http://www.who.int/mediacentre/factsheets/fs330/en/index.html. 